\title{
Climate Change Reduces the Mitigation \\ Obtainable from Sequestration in an Australian Farming System
}

Tas Thamo, Donkor Addai, Marit E. Kragt, Ross S. Kingwell, David J. Pannell and

Michael J. Robertson ${ }^{1}$

\begin{abstract}
Agricultural research on climate change generally follows two themes: (i) impact and adaptation or (ii) mitigation and emissions. Despite both being simultaneously relevant to future agricultural systems, the two are usually studied separately. By contrast, this study jointly compares the potential impacts of climate change and the effects of mitigation policy on farming systems in the central region of Western Australia's grainbelt, using the results of several biophysical models integrated into a whole-farm bioeconomic model. In particular, we focus on the potential for interactions between climate impacts and mitigation activities. Results suggest that, in the study area, farm profitability is much more sensitive to changes in climate than to a mitigation policy involving a carbon price on agricultural emissions. Climate change reduces the profitability of agricultural production and, as a result, reduces the opportunity cost of reforesting land for carbon sequestration. Nonetheless, the financial attractiveness of reforestation does not necessarily improve because climate change also reduces tree growth, and therefore, the income from sequestration. Consequently, at least for the study area, climate change has the potential to reduce the amount of abatement obtainable from
\end{abstract}

\footnotetext{
${ }^{1}$ Tas Thamo, Donkor Addai, Marit E. Kragt (email: marit.kragt@uwa.edu.au), Ross S. Kingwell, David J. Pannell and Michael J. Robertson are with the University of Western Australia School of Agriculture and Environment, University of Western Australia, Crawley, Western Australia, Australia. Tas Thamo, Marit E. Kragt and David J. Pannell are also with the University of Western Australia Centre for Environmental Economics and Policy, University of Western Australia, Crawley, Western Australia, Australia. Michael J. Robertson is also with CSIRO Agriculture, Floreat, Western Australia, Australia. Ross S. Kingwell is also at the Australian Export Grains Innovation Centre, South Perth, Western Australia, Australia.
} 
sequestration - a result potentially relevant to the debate about the desirability of sequestration as a mitigation option.

Keywords: Climate Change Impacts, Adaptation, Mitigation, Emissions, Agriculture, Interaction, Economics, Sequestration

\section{Introduction}

In studies of climate change and agriculture, the topics of (i) impact and adaptation and (ii) mitigation and emissions are typically addressed in isolation. For instance, a review of 221 studies modelling the impact of climate change on agriculture found that only $2 \%$ of studies considered the potential impacts of climate change on soil carbon levels, and only 3\% considered the potential impacts on farm emissions (White et al. 2011). However, the reality is that both sets of issues are important and that they may interact with each other.

It is possible that practices that mitigate emissions could also help with adaptation to climate change. For example, farmers may choose to adapt to climate change by switching from the production of agricultural crops to trees for carbon sequestration (Howden et al. 2010). In other words, there is potential for positive synergies between mitigation and the adaptation of agriculture to climate change (Smith and Olesen (2010)). Negative synergies are also possible: in some areas of eastern Australia climate change may encourage farmers to restructure their enterprise, away from cropping and into sheep production (Hertzler et al. 2013), which could increase methane emissions. It is also possible that changes in climate could reduce the efficacy of strategies to mitigate emissions. For example, in some cases the ability to increase and/or maintain carbon already sequestered in agricultural soils may decline under projected changes to climate (Grace et al. 2006; Hoyle et al. 2013; Liu et al. 2014; Conyers et al. 2015). This means that the performance of policies that encourage sequestration, such as Australia's Emission Reduction Fund - a policy in which landholders can undertake sequestering re-afforestation in return for marketable 'carbon credits' (Australian Government 2019) - may be compromised by climate change itself.

Smith and Olesen (2010) called for economic analysis of the effect of climate change impacts and adaptation strategies on the cost of policies aimed at mitigating emissions 
in the agriculture/land sectors. Of the analyses that have considered the effect of climatic changes on mitigation strategies/policies, many are purely biophysical (Liu et al. 2014; Xiong et al. 2014; Hobbs et al. 2016). Whilst biophysical models are useful for predicting how rates of emissions or sequestration from a given enterprise or land uses may alter under a changed climate, economic models are required to understand the effects of 'climate change on the financial performance of a farming enterprise and land-use choices (and therefore the cost of incorporating into a farming business those practices or land uses that mitigate emissions) (e.g., Reidsma et al. 2015).

A number of integrated modelling studies, incorporating economics and bio-physical aspects, have considered interactions between climate change and mitigation policy when projecting future land uses. Examples include case studies in the US (Mu et al. (2015) and Australia (Bryan et al. 2014; Connor et al. 2015; Bryan et al. 2016a; Bryan et al. 2016b; Grundy et al. 2016). These studies represent the connections between policy, land use, emissions and future climate change, at a broad scale. To achieve this requires some simplifications. For instance, the aforementioned Australian analyses do not represent economic interactions between farm enterprises, do not endogenously represent adaptations to the management of agricultural land in response to changes in climate $^{2}$, do not use process-based models to predict the impact of climate change on agricultural production, and do not account for elevated $\mathrm{CO}_{2}$ enhancing agricultural production.

Other studies make different compromises. A number have considered the effect of climate change policy in Australia with detailed, farm-level analysis (Petersen et al. 2003a; Petersen et al. 2003b; Flugge and Schilizzi 2005; Flugge and Abadi 2006; Kingwell 2009; Kragt et al. 2012; Thamo et al. 2013). However, none of these analyses also simultaneously considered the impact of future changes in climate, and how these changes may interact with mitigation policy, such as by affecting the economic viability of sequestration.

\footnotetext{
${ }^{2}$ Modelling adaptation as an endogenous process means that the model selects optimal changes in the farming system (e.g. land use and input usage) to minimise the negative impacts of climate change, or to maximise the benefits from adopting new opportunities that climate change creates.
} 
We aim to build on this latter group of studies by conducting a farm-level bioeconomic analysis comparing the prospective impacts and interactions between climate change and mitigation policy. We use process-based models to simulate the impact of climatic changes (including elevated $\mathrm{CO}_{2}$ ) on both agricultural production and reforestation for sequestration. We then incorporate these predictions into a detailed, whole-farm model that explicitly represents the interrelationships between different components of farm businesses and utilises optimisation techniques to adapt land-uses and management practices to changes in climate and policy.

\section{Methods}

In this study we evaluate how a representative mixed crop and livestock farm in the central wheatbelt of Western Australia would likely adapt to climate change. We consider a range of adaptation opportunities, including changes in enterprise mix (proportions of land allocated to crop production and livestock grazing) and fertilizer input intensity for a range of climate-change scenarios from mildly to severely warming and drying. We also evaluate the potential implications of two policy scenarios: one where farmers are required to pay a price per unit of greenhouse-gas emissions, and a second where farms can receive payments for emissions offsets resulting from switching land-use from crop and livestock production to trees for carbon sequestration.

\subsection{Study area}

Our study area is the central area of Western Australia's wheatbelt. At 5.2 million hectares (Finlayson et al. 2012), this is a large and important agricultural region in Australia. However, under suitable conditions (policy, economic and climatic), reforestation of this farmland could provide sequestration.

The region has a Mediterranean climate with dry, hot summers and cool winters during which the majority of precipitation occurs. The town of Cunderdin, near the centre of the study area (Figure 1), receives 360mm of rainfall (annual average 1957-2010). Farms are unirrigated, relying exclusively on this rainfall, and tend to be mixedenterprise businesses. Land uses include different rotational combinations of wheat, canola, lupin, barley and oats, and legume-based annual pastures. Sheep are grazed on pastures in winter/spring and on crop residues in summer, producing wool and meat. In autumn, livestock require a grain-based supplementary ration. Farms are mostly owner- 
operated, large and mechanised, with little hired labour apart from at times of crop seeding and harvest. Crops are sown in autumn, grown over winter and spring, and harvested in late spring or early summer. In most years, there is little rain between harvest and crop seeding the following year. Agriculture is export-focused and receives no government support in the form of payments, quotas, or subsidised crop insurance.

\subsection{MIDAS model}

To assess the economic impact of climate change simultaneously with different scenarios for mitigation policy, we use the whole-farm Model of an Integrated Dryland Agricultural System (MIDAS) (Kingwell and Pannell 1987). MIDAS is a steady-state deterministic model in which farm profitability is maximised (subject to various managerial, resource and financial constraints) by selecting the optimal combination of land uses and management practices for a 'typical' or average weather-year (Morrison et al. 1986). It is a complex and detailed model and one of its strength is its representation of the interdependencies and relationships between various aspects of the farming system. These include: the benefits of rotating crop types (nitrogen fixation and disease management); the impact of cropping phases on pasture regeneration; the influence of weed populations on crop yields; and crop residues being a fodder for livestock.

The MIDAS model for the study area has a long history of use (e.g., Petersen et al. 2003b; Kingwell 2009; Finlayson et al. 2012; Kragt et al. 2012; Thamo et al. 2013), and it was recently updated and re-validated by Thamo et al. (2017a). Consistent with contemporary farm businesses in this area, we assume a 3200 ha farm with eight soil types (these soils are described in more detail in Thamo et al. 2017a). It includes all land uses that typically occur in the study region (see previous section), plus the option of retiring land from production (should climate change render agriculture unprofitable). (Figure 1 near here)

Grain, livestock and fertiliser prices are based on the average real prices from 20092013. For inputs other than fertiliser we use 2013 prices. We express all monetary values in Australian dollars (on average from 2001-2015, AU\$1 was equal to $€ 0.64$ and US\$0.80).

The following sections describe how we adapt MIDAS to represent the impact of climate change and different scenarios for emissions policy. 


\subsection{Climate change impacts}

\subsubsection{Projections for study area}

The study region is predicted to get hotter and drier, particularly in the longer term. An analysis of the predictions of more than 40 Global Climate Models that underlie the Fifth Assessment Report of the Intergovernmental Panel on Climate Change (Hope et al. 2015) indicated with strong confidence that, across all seasons, mean temperatures will increase by an average of $0.5-1.1^{\circ} \mathrm{C}$ by 2030 , and by $1.2-4.0^{\circ} \mathrm{C}$ by 2090 compared to 1986-2005. In addition, June -November rainfall (effectively the growing season) will change by $+5 \%$ to $-15 \%$ by 2030 , and by $-5 \%$ to $-45 \%$ by 2090 . These predictions accord with those from other studies, and with changes already observed in the study region's climate (e.g., Hughes 2003; Hope et al. 2006; CSIRO and BoM 2007; Bates et al. 2008; Potgieter et al. 2013; Delworth and Zeng 2014). Indeed, the study region is one of the few instances where past regional changes in rainfall have been confidently attributed to climate change (Karoly 2014).

\subsubsection{Climate change scenarios}

The base-case climate used in this study consists of metrological observations for Cunderdin from 1957-2010, and an assumed atmospheric $\mathrm{CO}_{2}$ concentration of 390 ppm. Five climate-change scenarios are considered (Table 1). These scenarios reflect the near unanimous predictions in the literature that the study region will become hotter and drier, conditional on the future trajectory of $\mathrm{CO}_{2}$ levels. In particular, they reflect the strong correlation between $\mathrm{CO}_{2}$ increases and rainfall reductions predicted for the study area (see references in previous paragraph), even though such correlations might not be strong at a global level. The scenarios are created by adjusting all observations in the base-case dataset by the amounts shown in Table 1 . This approach to the development of climate scenarios_-also used by van Ittersum et al. (2003); Ludwig and Asseng (2006); Bryan et al. (2010); Bryan et al. (2011); Paudel and Hatch (2012); Thamo et al. (2017a) — changes the minimum and maximum temperatures, and the intensity but not frequency of precipitation.

(Table 1 near here)

\subsubsection{Modelling biophysical impact on agricultural production}

For each climate scenario, we simulate pasture growth using GrassGro® (version 3.2.6) (Moore et al. 1997) and crop yields using APSIM (Agricultural Production Systems Simulator, version 7.5) (Keating et al. 2003). These process-based models use soil data 
and daily weather data to drive detailed models of the growth of crop and pasture plant biomass and its conversion into saleable products. They have the capacity to model the effect of climate change, including elevated $\mathrm{CO}_{2}$, on plant growth (Moore 2012; Holzworth et al. 2014), and have been used for this purpose in the study region (e.g., Asseng et al. 2004; Ludwig et al. 2009; Ghahramani and Moore 2013).

The predictions of agricultural production under each climate scenario by GrassGro and APSIM are incorporated into MIDAS as follows: First, the simulation models are parameterised for each of MIDAS's eight soil types, such that the relative differences in yields and pasture growth between the different soil types predicted by the simulation models (on average, across the 53 years (1957-2010) of the base-case climate dataset) match those specified in MIDAS for an 'average weather year' (the accuracy and specification of this version of MIDAS has previously been checked and validated (Thamo et al. 2017a)). The simulation models are then run for each climate scenario in Table 1. The relative difference between the simulation model result for each climate scenario and the result with the base-case climate (when averaged over 53 years) is then used to scale the growth and yield potential of pastures and crops in MIDAS. This process is repeated for all soil types and land-uses, allowing the relative change in pasture or crop growth projected by the simulation models for every climate scenario, on every soil type, to be represented in MIDAS. In the case of pasture, the growingseason is divided into five phases, with pasture growth in each climate scenario assessed separately for each phase. This allows for the possibility of climate change impacting pasture production differently across the growing season. Preliminary simulations in GrassGro indicated that for a wide range of grazing intensities the relative impact of a given climate change scenario tended to be comparatively consistent. Nonetheless, the average result of simulations with two, four and eight grazing wethers per ha was used. The resultant changes in pasture productivity were then re-created in MIDAS and optimal stocking rates then endogenously selected.

The APSIM model we use had not been calibrated to model the impact of elevated $\mathrm{CO}_{2}$ on canola, lupin, oats and barley. Therefore our estimates of the relative effect of changes in precipitation-temperature- $\mathrm{CO}_{2}$ on the yields of these crops are based on APSIM's predictions for wheat (for which the model has been extensively calibrated). 
To estimate the effect of climate change on yield potential, independent of nutritional limitations, the highest yield obtained in APSIM simulations of each climate scenario with 40,90 and $140 \mathrm{kgN} / \mathrm{ha}$ is used when scaling growth of non-legume crops. The prospect that enhanced atmospheric $\mathrm{CO}_{2}$ could increase a crop's demand for nitrogen is then captured with MIDAS's nitrogen response curves that endogenously account for the interrelationship between yield potential, grain quality and crop nutrition.

\subsection{Modelling mitigation options}

We consider two ways in which mitigation policy could affect agriculture: (i) agriculture could provide emission offsets by sequestering carbon; and (ii) landholders could be required to buy permits or pay a tax for emissions that occur on-farm (with the cost of this permit or tax being set by the 'carbon price').

\subsubsection{Sequestration}

The use of agricultural land to sequester carbon is a much-discussed climate change mitigation option (e.g., Harper et al. 2007; Polglase et al. 2013; Bryan et al. 2014; Thamo and Pannell 2016 etc.). Indeed, under the Australia's Emission Reduction Fund, landholders can voluntarily undertake management changes to sequester carbon on their land and then claim and sell (at the carbon price) 'credits' for the carbon they have stored (ComLaw 2013). Eligible management options under this Australian policy include those that sequester carbon in the soil, and those that store carbon in vegetation, such as tree planting/re-forestation. The latter has had wider uptake in the Emissions Reduction Fund (Thamo 2017), and so we consider this mitigation option in our analysis.

To represent this mitigation opportunity we include in the MIDAS model the option for farmers to reforest their land with mallee trees (Eucalyptus loxophleba subsp. lissophloia) planted in block configuration. The amount of sequestration that could be claimed from these plantings is estimated with FullCAM (version 3.55) (Richards and Evans 2004), which is the model used to estimate sequestration in the Australian Government's Emissions Reduction Fund. Because FullCAM does not readily differentiate between soil type at a paddock/farm-scale (Hobbs et al. 2016), we adjust FullCAM's estimates to match each of MIDAS's eight soil types based on predictions by Farquharson et al. (2013), and the forestry model 3PG. 
To represent the effects of climate change, the estimates of sequestration are scaled based on the 3PG model's prediction of the effect of each climate scenario $\left(\mathrm{CO}_{2}\right.$, rainfall, and temperature changes) on sequestration rates for each soil type. The operation of $3 \mathrm{PG}$ and the growth modifiers it uses for elevated atmospheric $\mathrm{CO}_{2}$ are described in Landsberg and Sands (2011). For simplicity, we assume re-afforestation would occur once the climate had 'changed' to that scenario, and not whilst it was in the process of changing (this was also assumed when modelling agricultural crops). A sequestering land-use returning dynamically-varying income over a long time period is not directly compatible with MIDAS, which represents a perpetual cycle of growingseasons. Therefore, the net present value of sequestration revenue based on annual tree growth in each year was annualised over 25 years (using a real discount rate of 5\%), yielding an equivalent annual revenue from sequestration suitable for inclusion within the MIDAS framework (Thamo et al. 2017b). The time frame of 25 years was used because it is the minimum term for which participants in Australia's Emissions Reduction Fund program are required to commit to maintain a sequestration activity.

Carbon prices ranging from $\$ 5-\$ 100 / \mathrm{tCO}_{2}$-e are tested for each climate scenario. We assume that this carbon price, the opportunity cost of foregone agricultural production, and transaction costs would all remain constant in real terms throughout the analysed time frame. Values assumed for establishment and transaction costs plus additional details about the modelling of sequestration are described in the Supplementary Material.

\subsubsection{Agricultural emissions}

Farming is a significant source of emissions in some countries $(\sim 16 \%$ of emissions in Australia_-Department of the Environment 2015). Garnaut (2011) suggested that in the longer-term, the best policy response would be to apply a mandatory carbon price to agricultural (i.e., on-farm) emissions. While this has not yet happened, here we explore the consequences of it happening in future. 
To represent this scenario in MIDAS, we use the emission factors employed in Australia's national greenhouse gas accounting (National Inventory 2011) ${ }^{3}$ to quantify emissions from the following sources:

- $\mathrm{CO}_{2}$ from fuel combustion and urea hydrolysis;

- $\mathrm{N}_{2} \mathrm{O}$ from fertiliser, animal wastes, biological $\mathrm{N}$-fixation and crop residues; and

$-\mathrm{CH}_{4}$ from enteric fermentation.

Although climate change could affect the biophysical processes behind some of these emissions, this is not considered because: (a) these complex processes are multifaceted and interact with other factors such as moisture level, stage of crop growth; and (b) these changes would also have to be recognised in the actual emission factors used when pricing emissions. Consequently, climate-change-induced changes in emissions are limited to those resulting from structural adjustments to the farming system (changes in input use, land use, animal numbers, etc.).

\section{Results}

\subsection{Climate change impacts on the farming system}

With a base-case climate, the financially-optimal strategy for a typical farm in the study area involves cropping 2,548ha ( $~ 80 \%$ of the farm area) annually, with the remainder of the farming system under pasture (Table 2). Under the mildest climate-change scenario, farm returns increase by $1 \%$ compared to base-case. This is because of the positive effect of elevated $\mathrm{CO}_{2}$ and small increases in temperatures during the winter months. However, with the larger rainfall reductions and temperature increases assumed under other climate scenarios, this positive effect is outweighed by negative influences, and returns substantially decrease. Note that the annual net returns we report represent profit at full equity (i.e., no interest costs). They are the returns after deducting variable costs, fixed overheads and non-cash expenses (like depreciation) but not the opportunity cost of the capital invested in land, livestock and machinery.

Adaptations to adverse climate change include a large decrease in livestock numbers (Table 2). This is because pasture becomes less productive and the optimisation model

\footnotetext{
${ }^{3}$ The formulas and assumptions used when applying these emissions factors in MIDAS are detailed in Thamo et al. (2013).
} 
responds by allocating less area to pasture in the farming system. Land converted out of pasture is either placed under crop or retired from production. The 220 ha of land that is retired from production under most climate scenarios represents the most infertile, sandy soil on the farm. Another adaptive change is to reduce applications of nitrogen fertiliser (despite increases in the area cropped). This is because crops tend to have lower yield potential under most of the climate scenarios, making it economically optimal to apply less fertiliser.

(Table 2 near here)

Overall, on-farm emissions tend to fall as the severity of climate change increases (Figure 2). This is consistent with reductions in emissions observed when drier years are experienced in the study region under 'current' climatic conditions (Kingwell et al. 2016), and is primarily driven by a reduction in methane emissions from livestock (due to the decrease in sheep numbers shown in Table 2). Reduced emissions from fertiliser use, crop residues and nitrogen fixation play a smaller role.

(Figure 2 near here)

\subsection{Mitigation policy and interactions with climate impacts}

We now consider the implications of different options for mitigation policy, and how they may alter if the climate changes, starting with a policy where land can be voluntarily reforested to sequester carbon.

\subsubsection{Sequestration}

Table 3 shows how much of the farm would be reforested under various carbon prices and climate scenarios. For reforestation to become part of the optimal farming system with a base-case climate, more than $\$ 40 / \mathrm{tCO}_{2}$-e would need to be received from selling carbon credits, a figure that is broadly consistent with other Australian analyses (e.g., Flugge and Abadi 2006; Polglase et al. 2013; Thamo et al. 2013; Bryan et al. 2014; Hatfield-Dodds et al. 2015; Grundy et al. 2016).

Values of $7 \%, 33 \%$ and $43 \%$ appear repeatedly in Table 3 because they correspond to proportions of the farm occupied by given soil types. For instance, the $7 \%$ of the farming system that requires the lowest carbon price to be reforested represents the same infertile soil which is retired from production in the absence of sequestration policy in Table 2. For it to be optimal to reforest more area than this $7 \%$ requires a carbon price of around $\$ 80 / \mathrm{tCO}_{2}$-e. Although Table 3 indicates $43 \%$ of the farm would 
be reforested at $\$ 100 / \mathrm{tCO}_{2}$-e, in reality this percentage may be overestimated because with wide-scale reforestation, agricultural commodity prices could increase to some degree. The export orientation of production in the study area means that demand tends to be elastic, but not perfectly elastic.

(Table 3 near here)

Reforesting for sequestration does not become more attractive under the climate scenarios modelled. Instead, Table 3 shows that at many carbon prices, it is optimal to re-vegetate less land under the five climate scenarios than with the base-case climate. Given that traditional agricultural pursuits are less profitable under climate change (Table 2), it may seem counter-intuitive that reforesting agricultural land for sequestration does not therefore become more attractive. However, climate change also affects tree growth, reducing the amount of carbon sequestered by the reforestation of a given amount of the farming system (Figure 3). Lower sequestration rates mean less income from reforestation. Furthermore, if there is less capacity to adapt and alter costs under reforestation than under agriculture, the optimal area of reforestation is reduced, as seen in Table 2. Note that this reduction in the optimal area to reforest should not be interpreted as indicating that the growth of trees is necessarily more affected than crop and pasture growth, but rather that the economic performance of reforestation is more affected.

(Figure 3 near here)

If the rate of sequestration is lower (per unit of area reforested), and it is economicallyoptimal to reforest less area, the combined result is that the amount of sequestration obtainable for a given carbon price will decrease (Figure 4). In other words, in this environment, climate change reduces the cost-effectiveness of a mitigation policy based on sequestration. This result appears to be relatively robust; a sensitivity analysis of the effect of climate change on the supply of sequestration for a given carbon price is provided in the Supplementary Material. It shows that even if sequestration rates were $20 \%$ less sensitive to climatic change than the biophysical modelling predicts, the abatement obtainable for a given carbon price is still lower with climatic change. (Figure 4 near here)

\subsubsection{Emissions price but no sequestration}

We now consider the application of a mandatory carbon price to on-farm emissions, without a sequestration policy. With the 'stick' of the emissions price, yet no 'carrot' in 
the form of potential sequestration-income, this would be the worst-case policy scenario in terms of farm profit. It is therefore interesting to see how, compared to climate change, such a policy might impact profit. Table 4 shows the price on agricultural emissions (but with no sequestration policy) required to produce the same impact on farm returns as predicted under the climate scenarios (with no mitigation policy at all). In other words, what carbon price (without climate change) would be equivalent to each climate change scenario (without a carbon price)? The message from these results is that climate change has an impact equivalent to the charging of a very high price on agricultural emissions. For instance, the 'Small-Medium' climate scenario (a 10\% reduction in precipitation, $1.25^{\circ} \mathrm{C}$ increase in temperatures and $450 \mathrm{ppm}$ atmospheric $\mathrm{CO}_{2}$ ) has an impact on profit equivalent to a $\$ 104 / \mathrm{tCO}_{2}$-e carbon price on agricultural emissions with the base-case climate. The prices in Table 4 are much larger than recent prices in emissions policies around the world. For instance, Australia's carbon tax was $\$ 24.15 / \mathrm{tCO}_{2}$-e in 2014; at the conclusion of 2015, prices in the EU and South Korean Emission Trading Systems were equivalent to about AU\$14/tCO 2 -e and $\mathrm{AU} \$ 15 / \mathrm{tCO}_{2}$-e respectively (ICAP 2016); and $\mathrm{AU} \$ 12.10 / \mathrm{tCO}_{2}$-e is the average price in the Australian Government's Emission Reduction Fund, as of mid-2016 (CER 2016).

(Table 4 near here)

\subsubsection{Both sequestration and a carbon price on agricultural emissions}

In reality, if a carbon price were imposed on on-farm emissions it would likely be accompanied by a sequestration-credit scheme. Figure 5(a) shows the impact of an increasing carbon price under this policy situation, for each climate scenario. Returns initially decrease as the carbon price increases because the cost of agricultural emissions rises, reaching a minimum with a carbon price of about $\$ 75 / \mathrm{tCO}_{2}$-e. With further increases in the carbon price, the income from sequestration becomes greater than the cost of agricultural emissions and returns begin to increase. This in turn leads to more land being converted to trees for sequestration. The larger the area of trees, the more rapidly profit increases with an increase in carbon price. The increase in profit at high carbon prices is less pronounced under more severe climate scenarios. This is partly because on-farm emissions tend to be lower under these scenarios (Figure 2), which means that emission charges have less impact, and partly because climate change reduces sequestration so there is less potential to capitalise on high carbon prices with reforestation. 
The relative flatness of the curves in Figure 5(a) and the distance between them indicate that, with the exception of the most benign climate scenario, differences in the climate scenarios have much bigger effects on farm returns than a carbon price of $\$ 0$ to $\$ 100 / \mathrm{tCO}_{2}$-e.

(Figure 5 near here)

Our analysis does not explicitly consider the potential long-term impacts of climate change or climate policy on demographic trends, economic development, productivity, or terms of trade. However, to provide some insight into the implications of any change in commodity prices brought about by these factors, we test the effects of $\pm 20 \%$ changes in the real price of all agricultural outputs. With a $20 \%$ increase in commodity prices (Figure 5(b)), the returns under most climate scenario exceed the returns with a base-case climate in Figure 5(a). Nonetheless, the distance between the curves in Figure 5(b) indicates climate change is still having a large impact on returns. Under higher commodity prices, sequestration understandably provides less of a boost to returns at high carbon prices. Conversely, under lower commodity prices, sequestration becomes attractive and therefore begins to lift farm returns at lower carbon prices (Figure 5(c)). Even so, the carbon price at which returns are minimised and then begin to rise due to the uptake of sequestration is still higher with climate change than without it.

\section{Discussion}

Two key findings emerge from the results: (i) in this study area, climate change has the potential to reduce financial attractiveness of participating in a policy that aims to encourage sequestration through reforestation; and (ii) farm profitability appears to be more sensitive to climatic changes than to the implementation of a mitigation policy involving a carbon price on agricultural emissions.

\subsection{Impact of climate change on the cost-effectiveness of sequestration}

With larger changes in climate, the quantity of sequestration obtained from reforestation is reduced. This suggests that, at least for the study region, there could be risks for policies that rely heavily on this form of sequestration to meet mitigation targets. Under a changed climate, the abatement obtainable from reforestation declines (Figure 4) for both economic and biophysical reasons. Biophysically, as the climate warms and dries, the amount that would be sequestered by growing trees on a given area of land reduces 
(Figure 3). This means that with a warming and drying climate, if the same amount of area was reforested then, other things being equal, sequestration would likely provide less abatement in the study region. Of course the area reforested could also change. Table 3 showed fewer hectares being allocated to sequestration under a changed climate.

In the model results, the agricultural production system is adapted under climate change (e.g., management was changed, lowering input costs). In contrast, the costs associated with reforestation - planting/establishment and ongoing monitoring and auditing - are assumed fixed in this analysis. This contributes to the economic performance of sequestration being more affected by climate change than is agriculture. It is possible that adaptations or technical developments could reduce these costs and/or increase productivity of reforestation in the future. In terms of climate change impacting the efficacy of mitigation strategies, such developments are, however, only relevant if they are more advantageous in the presence of climate impacts than in their absence (Lobell 2014).

Although not captured in this analysis, another consideration about adaptability is that trees, once planted, are not easily adapted thereafter. In contrast, the annual cyclic nature of agriculture lends itself to the progressive adoption of adaptation strategies as they become available (e.g., Hertzler 2007).

Our results suggest that previous studies that did not consider the impact of climate change (Petersen et al. 2003a; Petersen et al. 2003b; Flugge and Schilizzi 2005; Flugge and Abadi 2006; Kingwell 2009; Thamo et al. 2013) may have overstated the mitigation potential offered by reforestation in the study area, and also that assuming that currently-realistic sequestration rates will persist may be erroneous (Hobbs et al. 2016). If so, they may have underestimated the price of sequestration contracts needed to attract landholders in the long-run.

A recent series of analyses (Bryan et al. 2014; Connor et al. 2015; Bryan et al. 2016a; Bryan et al. 2016b; Gao et al. 2016; Grundy et al. 2016) all employed a similar methodology that utilised equilibrium modelling to project economic growth, carbon prices and demand for agricultural commodities until 2050. In general, they predicted that reforestation would increase in competitiveness over time, such that substantial 
areas of Australian farmland will be converted to sequestering land uses, despite the impacts of climate change. While this seems to contradict our findings, their lowclimate-change scenarios involved the highest carbon price (which made sequestration more attractive). With climate and carbon prices both varying, it is difficult to discern the individual influence of either.

Their largest predictions of land-use change from agriculture to sequestration were associated with carbon prices in 2050 exceeding $\mathrm{AU} \$ 110 \mathrm{tCO}_{2}-\mathrm{e}$, and as high as AU \$200/tCO 2 -e (in 2010 dollars) (Bryan et al. 2016a). Whilst some believe that high prices will be required in the future if climate change is to be successfully addressed (e.g., Garnaut 2008; Cai et al. 2016), these prices are much higher than those featured in contemporary policies (as noted earlier), and higher than we considered in our analysis.

Furthermore, although when expressed as a generalisation at the national level, they predicted substantial areas of Australian farmland being reforested for sequestration, the strength of this finding varied at the region-level. Indeed, for our Western Australian study region, Connor et al. (2015) predicted that the level of reforestation would be considerably less than in the agricultural regions in eastern Australia that they analysed in detail, and less than the average level of reforestation across the continent. Finally, the above-cited collection of studies by Bryan and colleagues did not allow for farm management to be adapted, nor the possible beneficial effect of ' $\mathrm{CO}_{2}$ fertilisation' on agriculture.

Unlike our analysis, the equilibrium-modelling studies discussed above allowed them to consider the effect of land-use competition and the yield impacts of climate change on food prices. Interestingly, however, this inclusion should have increased the competiveness of agricultural land uses relative to reforestation, and so this difference in the models does not help account for differences in the findings.

Several factors could potentially change the economic viability of sequestration compared to our analysis. We assumed that the opportunity cost of foregone agricultural production and the carbon price would both remain constant in real terms. On the other hand, if opportunity costs decreased (increased) and/or carbon prices increased (decreased) in real terms, then sequestration would become more (less) attractive. Price feedbacks in response to climate change, a carbon price and/or the uptake of 
sequestering land uses could obviously change the relative attractiveness of different enterprises. Connor et al. (2015) found that such price feedbacks had little impact when Australian agriculture was considered in aggregate, but when considered at higher resolutions, location-specific impacts were much more pronounced.

Our estimates of sequestration rates were based on methodologies specified for the Australian Government's Emission Reduction Fund, which tend to be conservative. Different species of woody vegetation, and/or planting configurations other than mallee ‘block' plantings may offer greater sequestration (Paul et al. 2015). Given our analysis is focused on interactions with climate change rather than the financial attractiveness of sequestration per se, the above considerations only matter to the extent that their effect on the attractiveness of sequestration differs between the base-case and other climate scenarios.

The MIDAS model we used portrays a single year with 'average' weather. Consequently, we considered only changes in 'average' weather, not changes in extremes or variability, even though such changes are expected to occur with climate change. Changes in the riskiness of farming may modify farmers' decision in two ways: most farmers in the region are averse to risk and will seek to manage their farm to limit risk, and/or farmers will modify the year-to-year tactical decisions that they make in response to current weather conditions (Pannell et al. 2000). However, the benefit from including risk aversion in studies such as this is often limited (e.g., Pannell et al. 2000) and, in the context of interactions between climate change and mitigation policy, the omission of risk is only a limitation to the extent that with climate change there is an increase in the variability of income from traditional agricultural pursuits relative to sequestration. It is also worth noting that even if it is a steadier source of income, the sunk costs, irreversibility, and loss of flexibility associated with reforestation is likely to be a significant disincentive to landholders (e.g., Regan et al. 2015).

There is increasing pressure to keep global temperature increases below $1.5^{\circ} \mathrm{C}$, particularly since the Paris COP21 Conference. Many believe that achieving this will require emissions to be 'negative' in the future, through the deployment of strategies to actively remove carbon from the atmosphere, including sequestration (e.g., Smith 2016). In Australia, there has also been considerable government interest in using the agricultural sector as a major source of mitigation. Our finding that, in one of 
Australia's major agricultural regions, the prospects for carbon sequestration from trees may not be strong, and could worsen with climate change, is therefore a potentially important insight for policymakers. Worldwide, in other situations and different regions, the performance of sequestration is likely to vary, including its response to climate change. A more broadly relevant take-home message therefore is the need for greater recognition of the potential for interactions between future changes in climate and the cost-effectiveness of mitigation activities.

\subsection{Relative impacts of climate change and mitigation policy}

With the exception of the most benign scenario, climate change appears likely to have a greater effect on farm profitability in the study area than mitigation policy involving a carbon price on on-farm emissions. Nevertheless, a carbon price on agricultural emissions currently seems an unlikely prospect in Australia. This is partly because of the transaction costs that would likely be involved, and partly because of political concerns about the impact on the profitability of farmers, who tend to be price-takers in international markets. Indeed, because of agriculture's trade-exposure, if a carbon price were applied to agriculture then farms would likely be protected from its full impost (e.g., provided with a quantity of 'free permits') (Thamo et al. 2013). In this situation, the effect of a carbon price on farm incomes would be even lower than we have estimated.

In reality, costs of climate change under each climate scenario would be less than we have estimated, because of adaptations involving yet-to-be-developed strategies or technologies. Equally though, the impact of a carbon price to agriculture emissions could also be reduced by future technological developments or other breakthroughs that enable on-farm emissions to be more cost-efficiently mitigated.

Limitations of our analysis include that the response of canola, lupins, oats and barley to elevated $\mathrm{CO}_{2} /$ climate change was based (proportionally) on wheat's response to the same change. This was done following expert advice, as knowledge of these crops' response to $\mathrm{CO}_{2}$, and in particular, the calibration and parametrisation of crop simulation models to predict this response, is much less advanced than it is for wheat. We also assumed that changes to climate would occur equally across all months of the year. In reality, changes may be distributed unevenly, and crop yields in the study area 
are sensitive to precipitation and/or temperature changes at particular times of the year (Ludwig et al. 2009). Although reduced rainfall is expected in the study area, an increase in the intensity of rainfall events that do occur is also possible (predictions about rainfall intensity are more uncertain, so were not included in our climate scenarios) (Hope et al. 2015). In the sandy soil types that predominate much of the study area, high-intensity rainfall infiltrates quickly, meaning the moisture can percolate below the roots of annual agricultural plants (van Ittersum et al. 2003). Therefore if an increase in rainfall intensity was to occur, it could place deeper-rooted trees at a relative advantage. Lastly, MIDAS is a steady-state model, so it does not represent the path of farm management changes over time. We consider this to be of minor importance in the current study, as the main interest is on the effects of climate change and climate policy on farm management and land use in a given set of circumstances rather than on how they transition over time. Although beyond the scope of this analysis, dynamic consideration of the change from one climate state to another raises questions about transition rates (e.g., constant/linear transition, threshold/tipping-point transition, etc.) that may be a fertile topic for future analysis, particularly if combined with consideration of the 'option value' of the flexibility that land holders may forego with sequestering pursuits.

\section{Conclusion}

Changes in climate predicted for the central wheatbelt region of Western Australia appear likely to have a negative impact on farm profitability. A policy to impose a carbon price on on-farm emissions would also reduce farm profitability, although probably to a substantially lower extent than the impact of climate change. Projected climatic changes also reduce the cost-effectiveness of reforestation to sequester carbon, by reducing the rates of sequestration per land area. The extent to which these outcomes would occur in other regions is unclear. Elsewhere, climate change could potentially positively impact upon mitigation strategies like sequestration. Therefore, in order to develop successful agriculture/land-based mitigation policy, it is prudent to consider the potential impacts of future climate change on the management actions promoted by the policy. Analysis of the farm-level impacts of climate change and mitigation policy in isolation, as has typically occurred in much research to date, may hinder the development of effective policy responses to climate change. 


\section{Acknowledgments}

We thank Jenny Carter for her assistance with the 3PG modelling and Brett Bryan for his feedback on drafts of this manuscript. We acknowledge the University of Western Australia, the Grains Research and Development Corporation (grant number GRS177), and the ARC Centre of Excellence for Environmental Decisions (grant number CE1101014) for their funding support. Marit Kragt recieved funding from the Australian Research Council while finishing this paper (DE160101306).

The positions expressed by Donkor Addai in this article are not necessarily reflective of those of his present employer the Australian Bureau of Agricultural and Resource Economics and Sciences.

\section{References}

Asseng, S., Jamieson, P.D., Kimball, B., Pinter, P., Sayre, K., Bowden, J.W. and Howden, S.M. (2004). Simulated wheat growth affected by rising temperature, increased water deficit and elevated atmospheric $\mathrm{CO}_{2}$, Field Crops Research 85 , 85-102.

Australian Government (2019). Emissions Reduction Fund-Overview. Available from: http://www.environment.gov.au/system/files/resources/cef73480-9dea-4436-bb154882345ae9a5/files/erf-factsheet-overview.pdf [accessed 20 May 2019].

Bates, B.C., Hope, P., Ryan, B., Smith, I. and Charles, S. (2008). Key findings from the Indian Ocean Climate Initiative and their impact on policy development in Australia, Climatic Change 89, 339-354.

Bryan, B.A., Crossman, N.D., King, D. and Meyer, W.S. (2011). Landscape futures analysis: Assessing the impacts of environmental targets under alternative spatial policy options and future scenarios, Environmental Modelling \& Software 26, 8391.

Bryan, B.A., King, D. and Wang, E. (2010). Potential of woody biomass production for motivating widespread natural resource management under climate change, Land Use Policy 27, 713-725.

Bryan, B.A., Nolan, M., Harwood, T.D., Connor, J.D., Navarro-Garcia, J., King, D., Summers, D.M., Newth, D., Cai, Y., Grigg, N., Harman, I., Crossman, N.D., Grundy, M.J., Finnigan, J.J., Ferrier, S., Williams, K.J., Wilson, K.A., Law, E.A. and Hatfield-Dodds, S. (2014). Supply of carbon sequestration and biodiversity services from Australia's agricultural land under global change, Global Environmental Change 28, 166-181.

Bryan, B.A., Nolan, M., McKellar, L., Connor, J.D., Newth, D., Harwood, T., King, D., Navarro, J., Cai, Y., Gao, L., Grundy, M., Graham, P., Ernst, A., Dunstall, S., Stock, F., Brinsmead, T., Harman, I., Grigg, N.J., Battaglia, M., Keating, B., Wonhas, A. and Hatfield-Dodds, S. (2016a). Land-use and sustainability under intersecting global change and domestic policy scenarios: Trajectories for Australia to 2050, Global Environmental Change 38, 130-152.

Bryan, B.A., Runting, R.K., Capon, T., Perring, M.P., Cunningham, S.C., Kragt, M.E., Nolan, M., Law, E.A., Renwick, A.R., Eber, S., Christian, R. and Wilson, K.A. (2016b). Designer policy for carbon and biodiversity co-benefits under global change, Nature Climate Change 6, 301-305. 
Cai, Y., Lenton, T.M. and Lontzek, T.S. (2016). Risk of multiple interacting tipping points should encourage rapid $\mathrm{CO} 2$ emission reduction, Nature Climate Change 6, 520.

CER (2016). Carbon Abatement Contract Register. Available from: http://www.cleanenergyregulator.gov.au/ERF/project-and-contractsregisters/carbon-abatement-contract-register [accessed 20 May 2019].

ComLaw (2013). Carbon Credits (Carbon Farming Initiative) (Quantifying Carbon Sequestration by Permanent Mallee Plantings using the Reforestation Modelling Tool) Methodology Determination 2013. Australian Government, Canberra.

Connor, J.D., Bryan, B.A., Nolan, M., Stock, F., Gao, L., Dunstall, S., Graham, P., Ernst, A., Newth, D., Grundy, M. and Hatfield-Dodds, S. (2015). Modelling Australian land use competition and ecosystem services with food price feedbacks at high spatial resolution, Environmental Modelling \& Software 69, 141-154.

Conyers, M., Liu, D.L., Kirkegaard, J., Orgill, S., Oates, A., Li, G., Poile, G. and Kirkby, C. (2015). A review of organic carbon accumulation in soils within the agricultural context of southern New South Wales, Australia, Field Crops Research 184, 177-182.

CSIRO and BoM (2007). Climate change in Australia. Technical Report. Commonwealth Scientific and Industrial Research Organisation, Marine and Atmospheric Research, Aspendale, Australia.

Delworth, T.L. and Zeng, F. (2014). Regional rainfall decline in Australia attributed to anthropogenic greenhouse gases and ozone levels, Nature Geoscience 7, 583-587.

Department of the Environment (2015). National Inventory Report 2013 Volume 1. The Australian Government Submission to the United Nations Framework Convention on Climate Change, Commonwealth of Australia.

Farquharson, B., Abadi, A., Finlayson, J., Ramilan, T., Lui, D.L., Anwar, M., Clark, S., Robertson, S., Mendham, D., Thomas, Q. and McGrath, J. (2013). EverFarm ${ }^{\circledR}$ Climate adapted perennial-based farming systems for dryland agriculture in southern Australia. National Climate Change Adaptation Research Facility, Gold Coast.

Finlayson, J., Real, D., Nordblom, T., Revell, C., Ewing, M. and Kingwell, R. (2012). Farm level assessments of a novel drought tolerant forage: Tedera (Bituminaria bituminosa C.H. Stirt var. albomarginata), Agricultural Systems 112, 38-47.

Flugge, F. and Abadi, A. (2006). Farming carbon: an economic analysis of agroforestry for carbon sequestration and dryland salinity reduction in Western Australia, Agroforestry Systems 68, 181-192.

Flugge, F. and Schilizzi, S. (2005). Greenhouse gas abatement policies and the value of carbon sinks: Do grazing and cropping systems have different destinies?, Ecological Economics 55, 584-598.

Gao, L., Bryan, B.A., Nolan, M., Connor, J.D., Song, X. and Zhao, G. (2016). Robust global sensitivity analysis under deep uncertainty via scenario analysis, Environmental Modelling and Software 76, 154-166.

Garnaut, R. (2008). The Garnaut Climate Change Review: Final Report. Cambridge University Press, Port Melbourne, Victoria, Australia.

Garnaut, R. (2011). The Garnaut Review 2011: Australia in the Global Response to Climate Change. Cambridge University Press, New York.

Ghahramani, A. and Moore, A.D. (2013). Climate change and broadacre livestock production across southern Australia. 2. Adaptation options via grassland management, Crop and Pasture Science 64, 615-630.

Grace, P.R., Post, W.M. and Hennessy, K.J. (2006). The potential impact of climate change on Australia's soil organic carbon resources, Carbon Balance and Management 1:14. 
Grundy, M.J., Bryan, B.A., Nolan, M., Battaglia, M., Hatfield-Dodds, S., Connor, J.D. and Keating, B.A. (2016). Scenarios for Australian agricultural production and land use to 2050, Agricultural Systems 142, 70-83.

Harper, R.J., Beck, A.C., Ritson, P., Hill, M.J., Mitchell, C.D., Barrett, D.J., Smettem, K.R.J. and Mann, S.S. (2007). The potential of greenhouse sinks to underwrite improved land management, Ecological Engineering 29, 329-341.

Hatfield-Dodds, S., Schandl, H., Adams, P.D., Baynes, T.M., Brinsmead, T.S., Bryan, B.A., Chiew, F.H.S., Graham, P.W., Grundy, M., Harwood, T., McCallum, R., McCrea, R., McKellar, L.E., Newth, D., Nolan, M., Prosser, I. and Wonhas, A. (2015). Australia is 'free to choose' economic growth and falling environmental pressures, Nature 527, 49-53.

Hertzler, G. (2007). Adapting to climate change and managing climate risks by using real options, Australian Journal of Agricultural Research 58, 985-992.

Hertzler, G., Sanderson, T., Capon, T., Hayman, P., Kingwell, R., McClintok, A., Crean, J. and Randall, A. (2013). Will primary producers continue to adjust practices and technologies, change production systems or transform their industry? An application of real options. National Climate Change Adaptation Research Facility, Gold Coast, Australia.

Hobbs, T.J., Neumann, C.R., Meyer, W.S., Moon, T. and Bryan, B.A. (2016). Models of reforestation productivity and carbon sequestration for land use and climate change adaptation planning in South Australia, Journal of Environmental Management 181, 279-288.

Holzworth, D.P., Huth, N.I., deVoil, P.G., Zurcher, E.J., Herrmann, N.I., McLean, G., Chenu, K., van Oosterom, E.J., Snow, V., Murphy, C., Moore, A.D., Brown, H., Whish, J.P.M., Verrall, S., Fainges, J., Bell, L.W., Peake, A.S., Poulton, P.L., Hochman, Z., Thorburn, P.J., Gaydon, D.S., Dalgliesh, N.P., Rodriguez, D., Cox, H., Chapman, S., Doherty, A., Teixeira, E., Sharp, J., Cichota, R., Vogeler, I., Li, F.Y., Wang, E., Hammer, G.L., Robertson, M.J., Dimes, J.P., Whitbread, A.M., Hunt, J., van Rees, H., McClelland, T., Carberry, P.S., Hargreaves, J.N.G., MacLeod, N., McDonald, C., Harsdorf, J., Wedgwood, S. and Keating, B.A. (2014). APSIM - Evolution towards a new generation of agricultural systems simulation, Environmental Modelling \& Software 62, 327-350.

Hope, P., Abbs, D., Bhend, J., Chiew, F., Church, J., Ekström, M., Kirono, D., Lenton, A., Lucas, C., McInnes, K., Moise, A., Monselesan, D., Mpelasoka, F., Timbal, B., Webb, L. and P., W. (2015). Southern and South-Western Flatlands Cluster Report. In: Climate Change in Australia Projections for Australia's Natural Resource Management Regions: Cluster Reports. CSIRO \& Bureau of Meteorology, Australia.

Hope, P., Drosdowsky, W. and Nicholls, N. (2006). Shifts in the synoptic systems influencing southwest Western Australia, Climate Dynamics 26, 751-764.

Howden, S.M., Crimp, S. and Nelson, R. (2010). Australian agriculture in a climate of change. in Jubb I, Holper P, Cai W (eds.), Managing Climate Change. Papers from the Greenhouse 2009 Conference, pp 101-112. CSIRO, Melbourne.

Hoyle, F.C., D’Antuono, M., Overheu, T. and Murphy, D.V. (2013). Capacity for increasing soil organic carbon stocks in dryland agricultural systems, Soil Research 51, 657-667.

Hughes, L. (2003). Climate change and Australia: Trends, projections and impacts, Austral Ecology 28, 423-443.

ICAP (2016). Emissions Trading Worldwide: Status Report 2016. International Carbon Action Partnership, Berlin.

Karoly, D.J. (2014). Climate change: Human-induced rainfall changes, Nature Geoscience 7, 551-552. 
Keating, B.A., Carberry, P.S., Hammer, G.L., Probert, M.E., Robertson, M.J., Holzworth, D., Huth, N.I., Hargreaves, J.N.G., Meinke, H., Hochman, Z., McLean, G., Verburg, K., Snow, V., Dimes, J.P., Silburn, M., Wang, E., Brown, S., Bristow, K.L., Asseng, S., Chapman, S., McCown, R.L., Freebairn, D.M. and Smith, C.J. (2003). An overview of APSIM, a model designed for farming systems simulation, European Journal of Agronomy 18, 267-288.

Kingwell, R., Marie Jeanne, R. and Hailu, A. (2016). A longitudinal analysis of some Australian broadacre farms' greenhouse gas emissions, farming systems and efficiency of production, Agricultural Systems 146, 120-128.

Kingwell, R.S. (2009). The Carbon Challenge for Mixed Enterprise Farms, New Zealand Agricultural and Resource Economics Society's Annual Conference, Nelson.

Kingwell, R.S. and Pannell, D.J. (1987). MIDAS, A Bioeconomic Model of a Dryland Farm System. Pudoc, Wageningen.

Kragt, M.E., Pannell, D.J., Robertson, M.J. and Thamo, T. (2012). Assessing costs of soil carbon sequestration by crop-livestock farmers in Western Australia, Agricultural Systems 112, 27-37.

Landsberg, J.J. and Sands, P.J. (2011). Physiological Ecology of Forest Production: Principles, Processes and Models. Academic Press/Elsevier.

Liu, D.L., Anwar, M.R., O'Leary, G. and Conyers, M.K. (2014). Managing wheat stubble as an effective approach to sequester soil carbon in a semi-arid environment: Spatial modelling, Geoderma 214-215, 50-61.

Lobell, D.B. (2014). Climate change adaptation in crop production: Beware of illusions, Global Food Security 3, 72-76.

Ludwig, F. and Asseng, S. (2006). Climate change impacts on wheat production in a Mediterranean environment in Western Australia, Agricultural Systems 90, 159179.

Ludwig, F., Milroy, S. and Asseng, S. (2009). Impacts of recent climate change on wheat production systems in Western Australia, Climatic Change 92, 495-517.

Moore, A. (2012). Climate Change Adaptation in the Southern Australian Livestock Industries Meat \& Livestock Australia Ltd, Sydney.

Moore, A.D., Donnelly, J.R. and Freer, M. (1997). GRAZPLAN: Decision support systems for Australian grazing enterprises. III. Pasture growth and soil moisture submodels, and the GrassGro DSS, Agricultural Systems 55, 535-582.

Morrison, D.A., Kingwell, R.S., Pannell, D.J. and Ewing, M.A. (1986). A mathematical programming model of a crop-livestock farm system, Agricultural Systems 20, 243-268.

$\mathrm{Mu}$, J.E., Wein, A.M. and McCarl, B.A. (2015). Land use and management change under climate change adaptation and mitigation strategies: a U.S. case study, Mitigation and Adaptation Strategies for Global Change 20, 1041-1054.

National Inventory (2011). National Inventory Report 2009 Vol. 1. Department of Climate Change and Energy Efficiency, Canberra.

Pannell, D.J., Malcolm, B. and Kingwell, R.S. (2000). Are we risking too much? Perspectives on risk in farm modelling, Agricultural Economics 23, 69-78.

Paudel, K.P. and Hatch, L.U. (2012). Global Warming, Impact on Agriculture and Adaptation Strategy, Natural Resource Modeling 25, 456-481.

Paul, K.I., Roxburgh, S.H., England, J.R., de Ligt, R., Larmour, J.S., Brooksbank, K., Murphy, S., Ritson, P., Hobbs, T., Lewis, T., Preece, N.D., Cunningham, S.C., Read, Z., Clifford, D. and John Raison, R. (2015). Improved models for estimating temporal changes in carbon sequestration in above-ground biomass of mixedspecies environmental plantings, Forest Ecology and Management 338, 208-218. 
Petersen, E.H., Schilizzi, S. and Bennett, D. (2003a). Greenhouse gas and groundwater recharge abatement benefits of tree crops in south-western Australian farming systems, Australian Journal of Agricultural and Resource Economics 47, 211-231.

Petersen, E.H., Schilizzi, S. and Bennett, D. (2003b). The impacts of greenhouse gas abatement policies on the predominantly grazing systems of south-western Australia, Agricultural Systems 78, 369-386.

Polglase, P.J., Reeson, A., Hawkins, C.S., Paul, K.I., Siggins, A.W., Turner, J., Crawford, D.F., Jovanovic, T., Hobbs, T.J., Opie, K., Carwardine, J. and Almeida, A. (2013). Potential for forest carbon plantings to offset greenhouse emissions in Australia: Economics and constraints to implementation, Climatic Change 121, 161-175.

Potgieter, A., Meinke, H., Doherty, A., Sadras, V., Hammer, G., Crimp, S. and Rodriguez, D. (2013). Spatial impact of projected changes in rainfall and temperature on wheat yields in Australia, Climatic Change 117, 163-179.

Regan, C.M., Bryan, B.A., Connor, J.D., Meyer, W.S., Ostendorf, B., Zhu, Z. and Bao, C. (2015). Real options analysis for land use management: Methods, application, and implications for policy, Journal of Environmental Management 161, 144-152.

Reidsma, P., Wolf, J., Kanellopoulos, A., Schaap, B.F., Mandryk, M., Verhagen, J. and Van Ittersum, M.K. (2015). Climate change impact and adaptation research requires integrated assessment and farming systems analysis: A case study in the Netherlands, Environmental Research Letters 10, 045004.

Richards, G.P. and Evans, D.M.W. (2004). Development of a carbon accounting model (FullCAM Vers. 1.0) for the Australian continent, Australian Forestry 67, 277283.

Smith, P. (2016). Soil carbon sequestration and biochar as negative emission technologies, Global Change Biology 22, 1315-1324.

Smith, P. and Olesen, J.E. (2010). Synergies between the mitigation of, and adaptation to, climate change in agriculture, The Journal of Agricultural Science 148, 543552.

Thamo, T. (2017). Climate Change in Western Australian Agriculture: a Bioeconomic and Policy Analysis, PhD Thesis, School of Agricultural and Resource Economics, University of Western Australia.

Thamo, T., Addai, D., Pannell, D.J., Robertson, M.J., Thomas, D.T. and Young, J.M. (2017a). Climate change impacts and farm-level adaptation: Economic analysis of a mixed cropping-livestock system, Agricultural Systems 150, 99-108.

Thamo, T., Kingwell, R.S. and Pannell, D.J. (2013). Measurement of greenhouse gas emissions from agriculture: economic implications for policy and agricultural producers, Australian Journal of Agricultural and Resource Economics 57, 234252.

Thamo, T. and Pannell, D.J. (2016). Challenges in developing effective policy for soil carbon sequestration: perspectives on additionality, leakage, and permanence, Climate Policy 16, 973-992.

Thamo, T., Pannell, D.J., Kragt, M.E., Robertson, M.J. and Polyakov, M. (2017b). Dynamics and the economics of carbon sequestration: common oversights and their implications, Mitigation and Adaptation Strategies for Global Change 22, 1095-1111.

van Ittersum, M.K., Howden, S.M. and Asseng, S. (2003). Sensitivity of productivity and deep drainage of wheat cropping systems in a Mediterranean environment to changes in $\mathrm{CO}_{2}$, temperature and precipitation, Agriculture, Ecosystems \& Environment 97, 255-273. 
White, J.W., Hoogenboom, G., Kimball, B.A. and Wall, G.W. (2011). Methodologies for simulating impacts of climate change on crop production, Field Crops Research 124, 357-368.

Xiong, X., Grunwald, S., Myers, D.B., Ross, C.W., Harris, W.G. and Comerford, N.B. (2014). Interaction effects of climate and land use/land cover change on soil organic carbon sequestration, Science of the Total Environment 493, 974-982. 


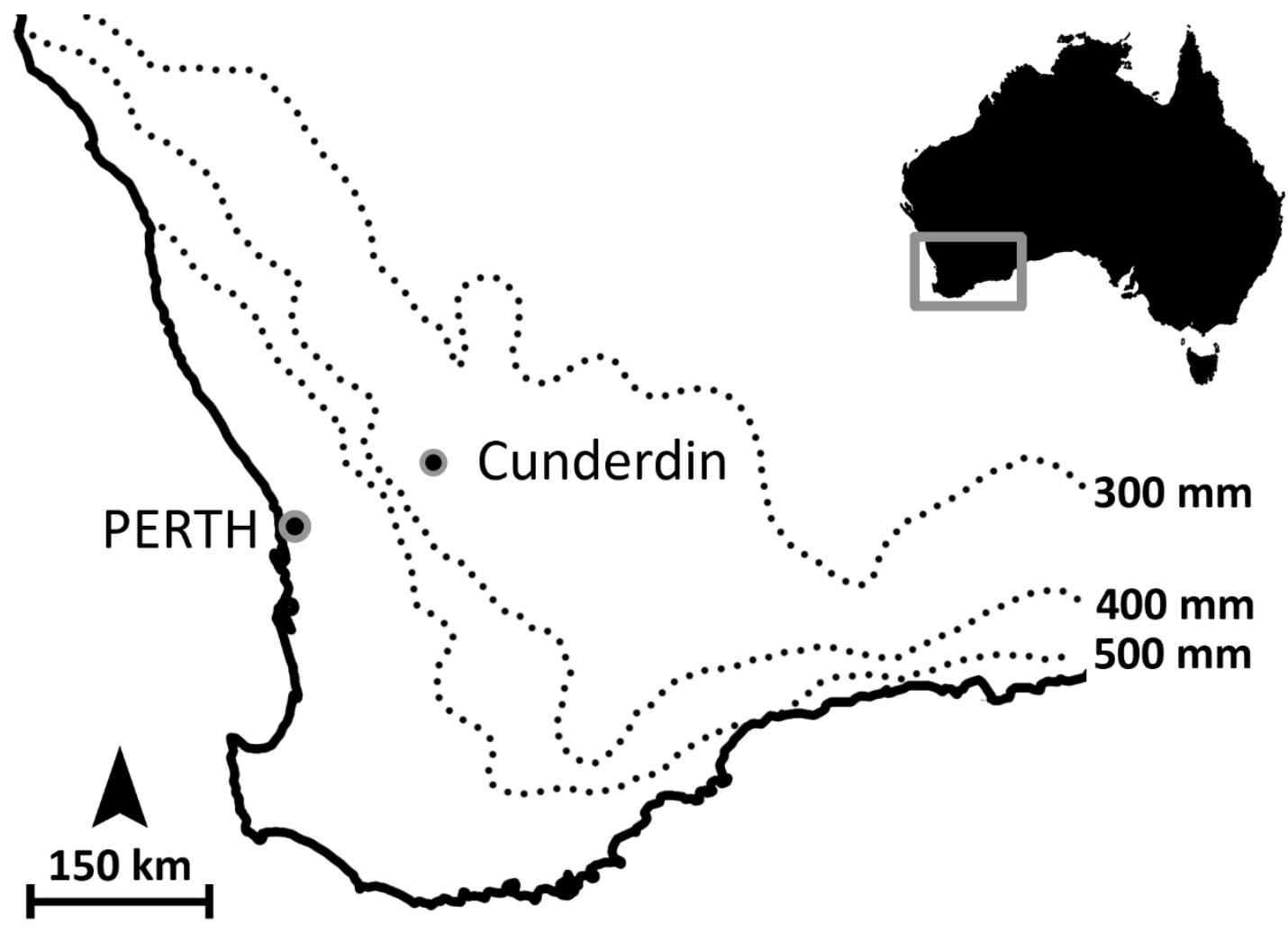

Figure 1. The representative farm was based on the Cunderdin district in the centre of Western Australia's Wheatbelt. Dotted isohyets show average historically-observed (pre-1997) annual rainfall. 


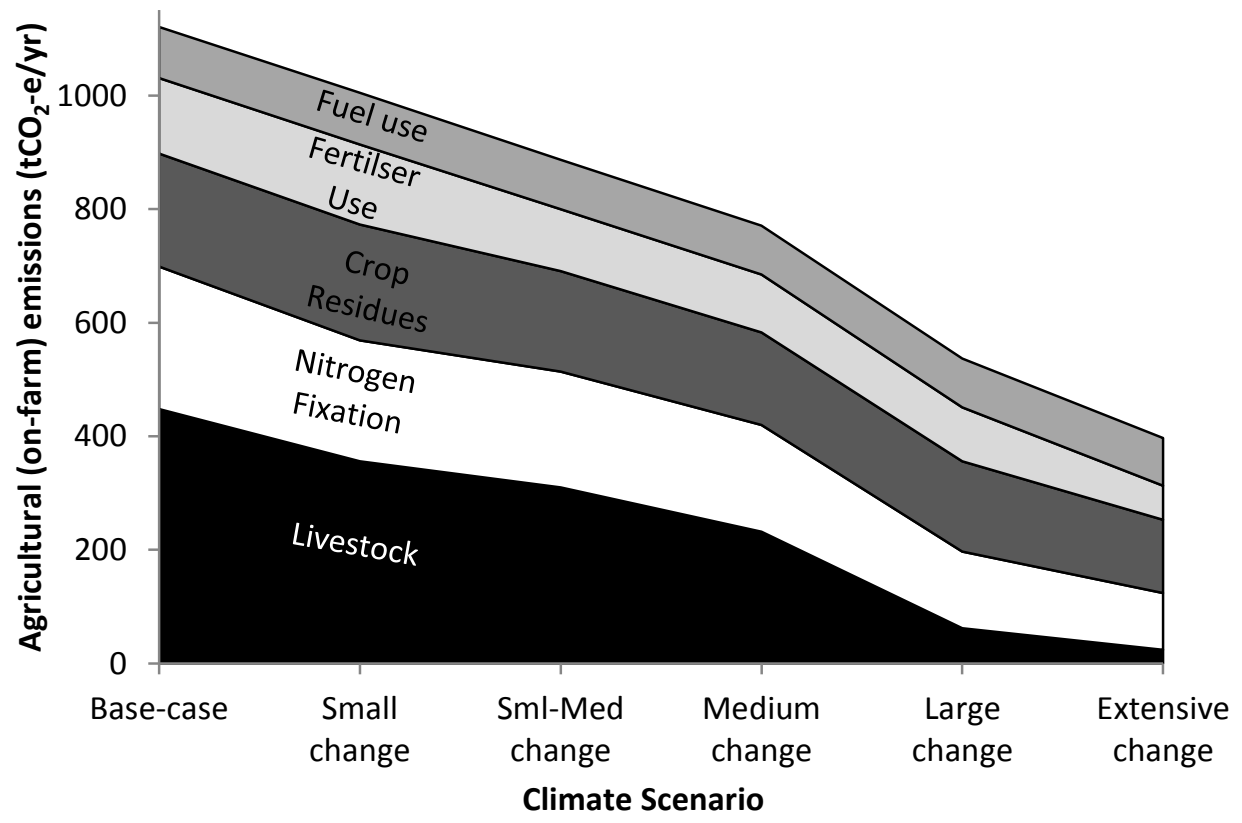

Figure 2. Emissions profile of the farming system under each climate scenario. 


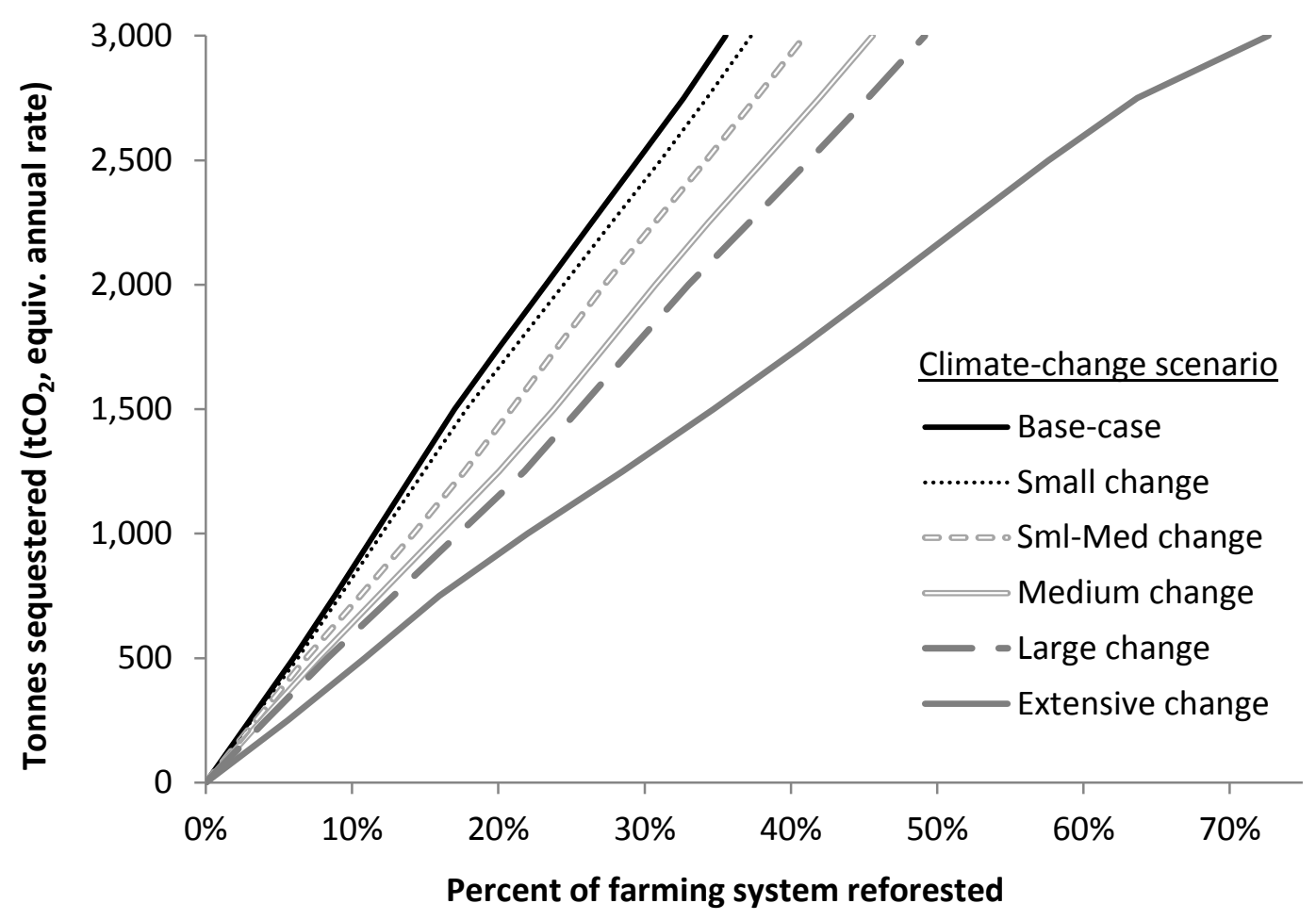

Figure 3. As the extent of the changes in climate increases, the amount of sequestration obtainable by reforesting a given amount of farm land declines. 


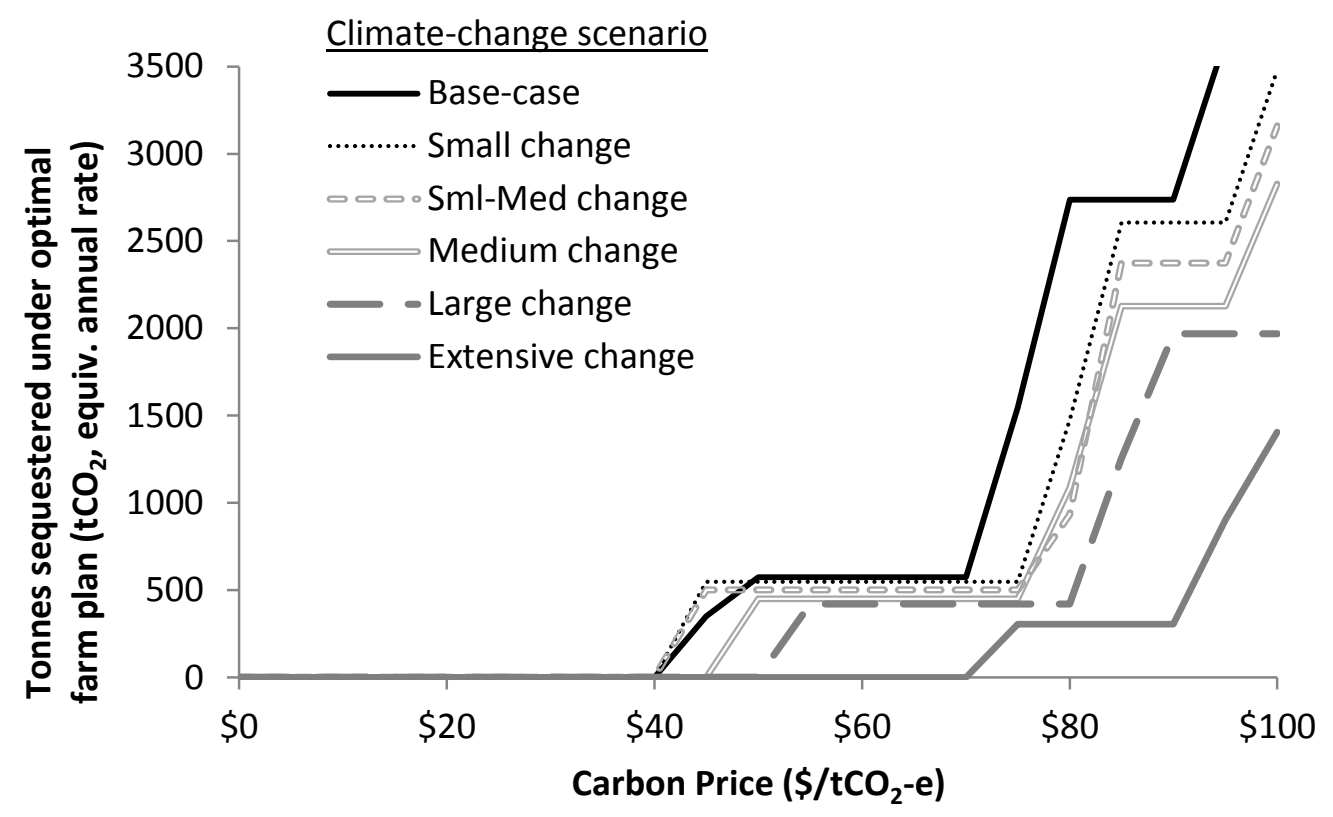

Figure 4. The carbon price required for the production of a given quantity of sequestration to be economically attractive tends to increase as the extent of climate change increases. 

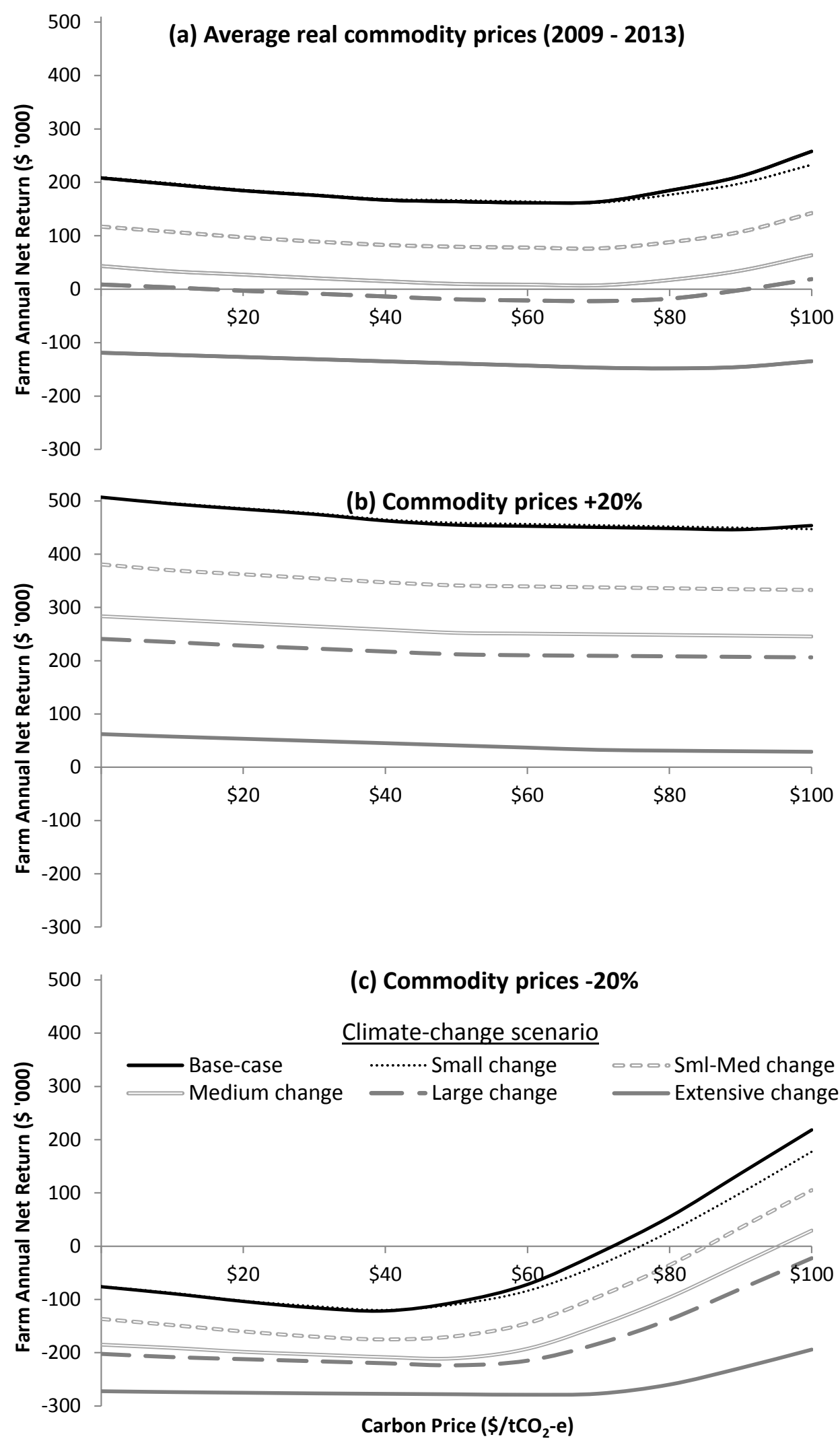

Figure 5. The impact of a carbon price on farm annual net returns (with the option of participating in sequestration policy) under different climate scenarios and: (a) average real; (b) 20\% increase; or (c) 20\% decrease in commodity prices. Climate-change scenario: 
Table 1. The five climate scenarios analysed.

\begin{tabular}{lccc}
\hline Scenario & $\mathbf{C O}_{2}(\mathbf{p p m})$ & Precipitation reduction $(\%)$ & Temperature increase $\left({ }^{\circ} \mathbf{C}\right)$ \\
\hline Small change & 425 & -5 & 0.50 \\
Small-Medium change & 450 & -10 & 1.25 \\
Medium change & 475 & -15 & 2.00 \\
Large change & 525 & -20 & 2.50 \\
Extensive change & 575 & -30 & 4.00 \\
\hline
\end{tabular}

Table 2. Characteristics of the typical, economically-optimal farming system in the study area and how they may change with climate change (percent change compared to base-case climate shown in parentheses).

\begin{tabular}{|c|c|c|c|c|c|c|}
\hline $\begin{array}{l}\text { Climate } \\
\text { Scenario }\end{array}$ & $\begin{array}{c}\text { Crop } \\
\text { area (ha) }\end{array}$ & $\begin{array}{c}\text { Pasture } \\
\text { area (ha) }\end{array}$ & $\begin{array}{l}\text { Sheep flock } \\
\left(\text { DSE }^{\mathrm{a}}\right)\end{array}$ & $\begin{array}{l}\text { Fertiliser } \\
\text { (tonnes) }^{\mathbf{b}}\end{array}$ & $\begin{array}{l}\text { Retired } \\
\text { Land (ha) }\end{array}$ & $\begin{array}{l}\text { Farm annual net } \\
\text { return }(\$ 1000)\end{array}$ \\
\hline Base-case & 2,548 & 652 & 2,545 & 91 & - & $\$ 208$ \\
\hline Small change & $2,613(3 \%)$ & $587(-10 \%)$ & $1,992(-22 \%)$ & $(6 \%)$ & - & $\$ 209$ \\
\hline Sml-Med change & $2,558(0 \%)$ & $422(-35 \%)$ & $1,736(-32 \%)$ & $74(-18 \%)$ & 220 & $\$ 117 \quad(-44 \%)$ \\
\hline Medium change & $2,548(0 \%)$ & $432(-34 \%)$ & $1,296(-49 \%)$ & $70(-24 \%)$ & 220 & $\$ 43 \quad(-79 \%)$ \\
\hline Large change & $2,660(4 \%)$ & $320(-51 \%)$ & $347(-86 \%)$ & $65(-28 \%)$ & 220 & $\$ 9 \quad(-96 \%)$ \\
\hline Extensive change & $2,713(6 \%)$ & $267(-59 \%)$ & $135(-95 \%)$ & $41(-55 \%)$ & 220 & $\$-119(-157 \%)$ \\
\hline
\end{tabular}

$\mathrm{a}_{\text {‘dry sheep equivalents' }}{ }^{\mathrm{b}}$ Total tonnes of synthetic elemental nitrogen (applied to cereals \& canola only)

Table 3. The optimal percentage of the farming system reforested for sequestration under various carbon price and climate scenarios.

\begin{tabular}{lcccccc}
\hline $\begin{array}{l}\text { Carbon } \\
\text { Price } \\
(\$ / \text { tCO }\end{array}$ & \multicolumn{7}{c}{-e $)$} & Base-case & $\begin{array}{c}\text { Small } \\
\text { change }\end{array}$ & $\begin{array}{c}\text { Sml-Med } \\
\text { change }\end{array}$ & $\begin{array}{c}\text { Medium } \\
\text { change }\end{array}$ & $\begin{array}{c}\text { Large } \\
\text { change }\end{array}$ & $\begin{array}{c}\text { Extensive } \\
\text { change }\end{array}$ \\
\hline$\$ 40$ & - & - & - & - & - & - \\
$\$ 50$ & $7 \%$ & $7 \%$ & $7 \%$ & $7 \%$ & - & - \\
$\$ 60$ & $7 \%$ & $7 \%$ & $7 \%$ & $7 \%$ & $7 \%$ & - \\
$\$ 70$ & $7 \%$ & $7 \%$ & $7 \%$ & $7 \%$ & $7 \%$ & - \\
$\$ 80$ & $33 \%$ & $18 \%$ & $13 \%$ & $17 \%$ & $7 \%$ & $7 \%$ \\
$\$ 90$ & $33 \%$ & $33 \%$ & $33 \%$ & $33 \%$ & $33 \%$ & $7 \%$ \\
$\$ 100$ & $43 \%$ & $43 \%$ & $43 \%$ & $43 \%$ & $33 \%$ & $33 \%$ \\
\hline
\end{tabular}


Table 4. The carbon price on agricultural emissions that results in the same net returns under a base-case climate scenario, as would occur under each climate scenario with a carbon price of zero. In these results, there is no reward for on-farm sequestration of carbon.

\begin{tabular}{lc}
\hline $\begin{array}{l}\text { Climate } \\
\text { Scenario }\end{array}$ & $\begin{array}{l}\text { Impact of climate scenario on net returns is equivalent to (under a base- } \\
\text { case climate) a carbon price }\left(\$ / \mathbf{C O}_{2} \text {-e) on agricultural emissions of: }\right.\end{array}$ \\
\hline Small change & $-\$ 1.1^{\text {a }}$ \\
Small-Medium change & $\$ 104$ \\
Medium change & $\$ 213$ \\
Large change & $\$ 268$ \\
Extensive change & $\$ 473$ \\
\hline
\end{tabular}

${ }^{\mathrm{a}}$ Price is negative because net returns increase with this climate scenario 